Cytotherapy, 2010; Early Online, 1-8

informa

healthcare

ORIGINAL ARITICLE

\title{
Cryopreservation of mononuclear cells before extracorporeal photochemotherapy does not impair their anti-proliferative capabilities
}

\author{
ETIENNE MERLIN ${ }^{1,2}$, DALIL HANNANI ${ }^{3,4,6}$, RICHARD VEYRAT-MASSON $^{1,5}$, \\ JACQUES CHASSAGNE ${ }^{1}$, FRAÇOISE GABERT ${ }^{3,4,6}$, MARC BERGER ${ }^{1,5}$, \\ FRANÇOIS DEMÉOCQ ${ }^{1,2,5}$, JOËL PLUMAS ${ }^{3,4,6} \&$ JUSTYNA KANOLD ${ }^{1,2,5}$
}

${ }^{1}$ CHU Clermont-Ferrand, Centre Régional de Cancérologie et Thérapie Cellulaire Pédiatrique, Hôtel-Dieu, ClermontFerrand, France, ${ }^{2}$ INSERM CIC 501, Clermont-Ferrand, France, ${ }^{3}$ Univeristé foseph Fourier, Grenoble, France, ${ }^{4}$ INSERM U823, Immunobiologie et Immunothérapie des cancers, La Tronche, France, ${ }^{5}$ Clermont-Université, Université d'Auvergne, Clermont-Ferrand, France, and ${ }^{6}$ EFS Rhone-Alpes, La Tronche, France

\begin{abstract}
Background aims. The clinical benefits of extracorporeal photochemotherapy (ECP) are well recognized, but its clinical use is limited by logistical difficulties, especially because of the need to perform repeated aphereses. The cryopreservation of mononuclear cells could allow maintenance of the ECP schedule while reducing the number of aphereses. The aim of this work was to assess whether previous cryopreservation impairs the immunomodulatory function of ECP-treated peripheral blood mononuclear cells (PBMC). Methods. Fresh or previously cryopreserved PBMC were exposed to ECP and added on day 0 into a mixed leukocyte reaction. Proliferation of alloreactive lymphocytes was measured by carboxyfluorescein succinimidyl ester (CFSE) dye dilution. Apoptosis was quantified by annexin-7AAD staining. Results. ECP-induced apoptosis was slightly increased in cryopreserved cells but the kinetics of apoptosis were similar to fresh cells. Lymphocytes stimulated in the presence of ECP-treated PBMC displayed a significant decrease in proliferation. The suppression was enforced when ECP-treated cells had been activated previously by allogeneic stimulation. Cryopreservation before ECP exposure did not impact apoptosis triggering or anti-proliferative properties of ECP-treated cells. Conclusions. Cryopreservation before ECP does not impair the immunomodulatory effects of treated cells. These data warrant investigation of the clinical use of cryopreserved PBMC for ECP.
\end{abstract}

Key Words: alloreactivity, carboxyfluorescein succinimidyl ester, human, pre-clinical study

\section{Introduction}

Extracorporeal photochemotherapy (ECP) is an immunomodulatory cellular therapy relying on the injection of autologous cell products exposed to ultraviolet (UV) in the presence of a photosensitizer. The cell product is obtained by the isolation of white blood cells by cytapheresis and their subsequent ex vivo exposure to 8-methoxypsoralen (8-MOP) and UV-A radiation (1). Treated cells are then reinfused into the patient. Several injections of the cell products are needed to obtain clinical improvement.

How ECP is able to induce immune tolerance without immunosuppression has still not been elucidated fully. Its mechanism of action involves lymphocyte $(2,3)$ and monocyte $(4)$ apoptosis, and several mechanisms have been hypothesized in humans, such as the involvement of tolerogenic antigen-presenting cells, production of immunosuppressive cytokines and generation of regulatory $\mathrm{T}$ cells $(5,6)$. However, until now none has been clearly related to the efficacy of ECP in humans.

To date, the main three indications are cutaneous T-cell lymphoma (CTCL) (7), graft-versus-host disease (GvHD) (6) and solid organ rejection (5). However, its original mechanism of action combined with the absence of generalized immunosuppression

Correspondence: Etienne Merlin, Centre Régional de Cancérologie et Thérapie Cellulaire Pédiatrique, CHU Estaing, 1 Place Lucie Aubrac, 63001 ClermontFerrand, France. E-mail: e_merlin@chu-clermontferrand.fr 
or side-effects makes ECP a very attractive approach for safely treating a wide variety of T-cell mediated pathologies (8). Depending on the clinical situation, the treatment schedule varies from three sessions a week to two sessions a month. Hence, the main obstacles to overcome for the widespread use of ECP are the logistical and psychologic issues secondary to the performance of several apheresis procedures per week for several weeks.

The French technique for ECP, as described by Georges Andreu in 1991 (9), comprises two distinct steps: (a) collection of peripheral blood mononuclear cells (PBMC) by apheresis and (b) treatment of the collection bag in the cell therapy laboratory. This technique makes it possible to cryopreserve the PBMC before UV irradiation. This approach could usefully diminish the number of apheresis runs but it is not known whether cryopreservation affects the properties of ECP-treated cells. This in vitro study investigated whether cryopreservation of PBMC prior to ECP impairs their in vitro immunomodulatory properties after UV exposition. Using a model of allogeneic mixed leukocyte reaction (MLR), we show that cryopreserved cells exhibit similar antiproliferative capabilities to fresh cells.

\section{Methods}

\section{Model}

The aim of our model was to reproduce an allogeneic conflict resembling the situation where a patient with GvHD is treated with ECP (Figure 1). In this situation, the ECP-treated bag contains alloreactive and resting mononuclear donor cells. The study enrolled six pairs of unrelated healthy volunteers; in each pair, one volunteer was considered as the donor (D) and the other as the recipient $(\mathrm{R})$. To obtain alloreactive cells, donor cells were primarily exposed to recipient cells. This step consisted of a first-run MLR. After a 7-day culture, the alloreactive cells were harvested. Naive ECP-treated cells $\left(\mathrm{D}_{\mathrm{ECP}}\right)$ or alloreactive ECPtreated cells $\left(\mathrm{D}_{\mathrm{SENS}+\mathrm{ECP}}\right)$ were added to a second MLR together with naive fresh cells from $\mathrm{D}$ and $\mathrm{R}$. Our judgment criterion was the intensity of the alloreactive proliferation in this second MLR.

\section{PBMC sampling and isolation}

Blood donations in this study conformed with local ethical committee requirements, and informed consent was obtained. Venous blood (30 mL) was collected in ethylene diamine tetra acetic acid (EDTA). PBMC were isolated by density-gradient centrifugation over Ficoll-Histopaque (Saint-Quentin Fallavier Sigma-Aldrich, St-Quentin Fallavier, France). The isolated cells were then washed twice in phosphatebuffered saline (PBS; Gibco, Cergy-Pontoise, France). Stimulating PBMC were irradiated at 30 Gy.

\section{Generation of $D$ to $R$ alloreactive cells (first $M L R$ )}

A first-run MLR was performed to obtain alloreactive cells from $\mathrm{D}$ cells stimulated by $\mathrm{R}$ cells; $10 \times 10^{6}$ reactive PBMC from $\mathrm{D}$ were cultured with $10 \times 10^{6}$ 30-Gy irradiated stimulator PBMC $\mathrm{R}^{*}$ for 7 days in a Falcon tube in $10 \mathrm{~mL}$ Dutch-modified RPMI-1640 (Gibco) supplemented with $10 \%$ fetal calf serum (FBS; Gibco, Cergy-Pontoise, France), L-glutamine, streptomycin and penicillin (Sigma-Aldrich). After 7 days, the cells were centrifuged, washed twice in PBS and treated with ECP.

\section{Generation of immunomodulatory donor cells (psoralen and UV-A (PUV-A) exposure/ECP)}

ECP was performed using the Vilber-Lourmat procedure, as described previously (10). Briefly, $5 \times 10^{6}$ PBMC were diluted in $20 \mathrm{~mL}$ normal saline solution to obtain a final hematocrit $<1 \%$, and 8-methoxypsoralen was added at $200 \mathrm{ng} / \mathrm{mL}$. After a 3-min incubation, cells were transferred into a UV-A transparent bag (Macopharma, Tourcoing, France) and exposed to UV-A light $(340 \mathrm{~nm})$ at $2 \mathrm{~J} / \mathrm{cm}^{2}$ for 10 min (UVA-matic; Macopharma, Tourcoing, France).

\section{Carboxyfluorescein succinimidyl ester labeling}

Carboxyfluorescein succinimidyl ester (CFSE) is a green fluorochrome that is retained in the cells for several weeks without inducing problems of viability (at suitable concentrations). During each cellular division, CSFE is distributed in a strictly dichotomic fashion between both daughter cells. Cytometric analysis of its decrease thus makes it possible to follow cell proliferation (11). This method has proved suitable for lymphocyte studies in vitro (12). In our experiments, $2.5 \times 10^{6} \mathrm{PBMC}$ from D were suspended in $2 \mathrm{~mL}$ PBS $(0.1 \%) /$ bovine serum albumin (BSA) buffer. Cells were labeled with $1 \mu \mathrm{mol} / \mathrm{L} \mathrm{CFSE}$ (Molecular Probes, Eugene, OR, USA) for $5 \mathrm{~min}$ at $37^{\circ} \mathrm{C}$. Labeling was stopped by adding $30 \mathrm{~mL}$ cold RPMI containing $10 \%$ FCS, after which the cells were maintained in ice for $5 \mathrm{~min}$. Cells were centrifuged $\left(800 \mathrm{~g}\right.$ for $10 \mathrm{~min}$ at $20^{\circ} \mathrm{C}$ ) and the supernatant removed. Cells were washed twice in PBS then suspended in $5 \mathrm{~mL}$ RPMI with $10 \%$ FCS.

\section{Cryopreservation and thawing of PBMC}

We used the same protocol as for hematopotietic progenitor cell cryopreservation in clinical routines (13); $8 \times 10^{6}$ density-gradient isolated PBMC were 


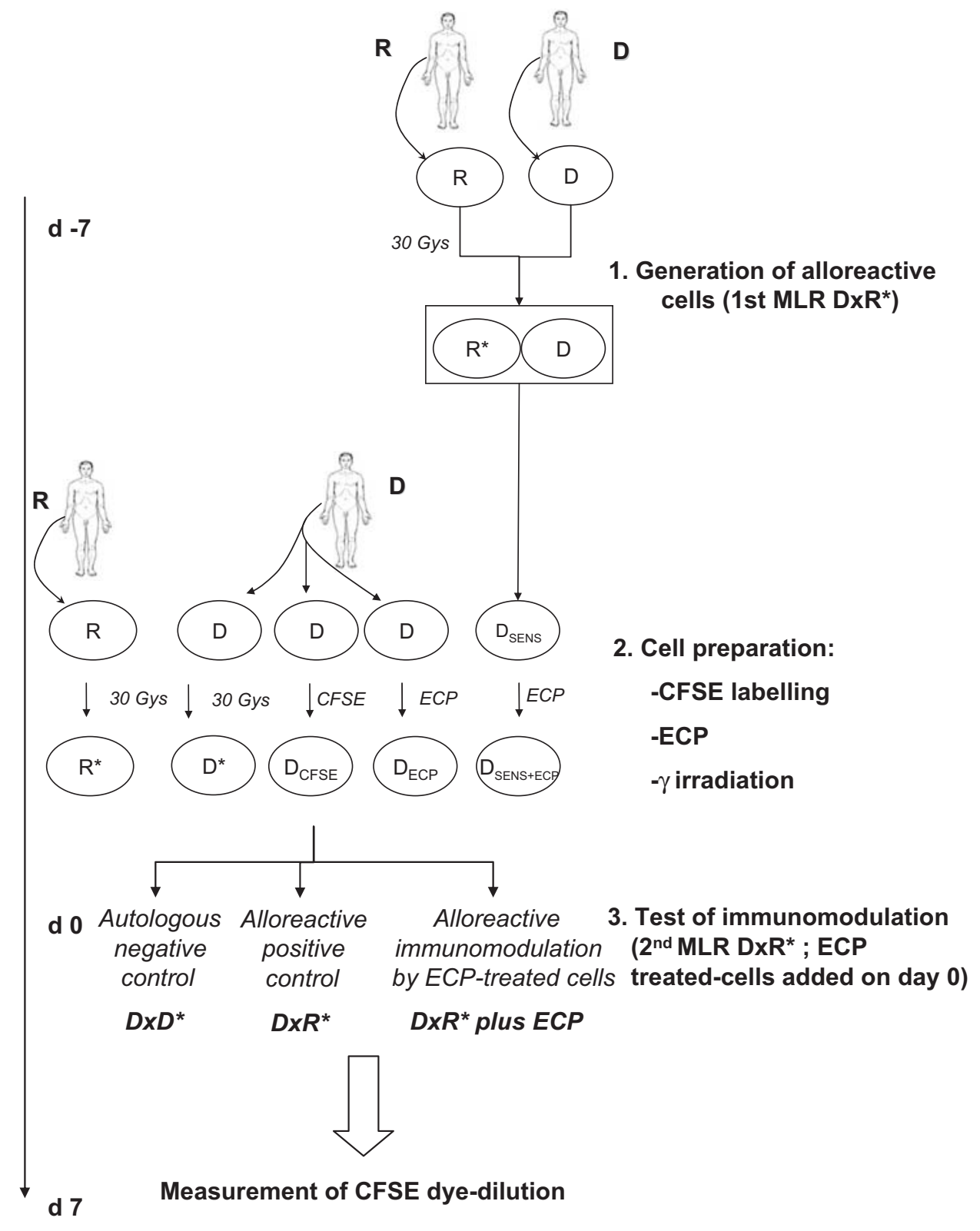

Figure 1. Scheme of the model of immunomodulation by ECP-treated cells in an alloreactivity setting. The aim of this model was to mimic the situation were a patient with GvHD is treated with ECP. Six couples of healthy volunteers were enrolled in the study; in each pair, one was considered the donor (D) and the other as the recipient ${ }^{\circledR}$. To obtain alloreactive cells, we employed a first step of sensitizing $\mathrm{D}$ to $\mathrm{R}$ in a MLR with responsive cells from $\mathrm{D}$ and 30-Gy irradiated stimulator cells from $\mathrm{R}\left(\mathrm{D} \times \mathrm{R}^{*}\right)$. After a 7-day culture, the alloreactive 'sensitized' cells $\left(D_{\text {SENS }}\right)$ were harvested and treated with ECP $\left(D_{\text {SENS }+E C P}\right)$. Either fresh cells $\left(D_{\text {ECP }}\right)$ or $D_{\text {SENS }+ \text { ECP }}$ were added in a second $\operatorname{MLR}\left(\mathrm{D} \times \mathrm{R}^{*}\right)$. Reactive cells were labeled with CFSE $\left(\mathrm{D}_{\mathrm{CFSE}}\right)$ to allow measurement of cell proliferation. In each experiment, we measured the inhibition of alloreactive proliferation as a result of the presence of ECP-treated cells.

resuspended in $5 \mathrm{~mL}$ PBS $+5 \% \mathrm{FCS}$ and transferred into $10-\mathrm{mL}$ cryobags (Baxter, Maurepas, France). Five milliliters of ice-cold cryoprotective solution containing 7\% dimethyl sulfoxide (DMSO), 10\% serum albumin and $83 \%$ hydroxyethylstarch were added slowly. Immediately after the cryoprotective solution was added, specimens were transferred to a $-80^{\circ} \mathrm{C}$ freezer overnight. This simplified method of uncontrolled-rate freezing lowers specimen temperatures by approximately $1-2^{\circ} \mathrm{C} / \mathrm{min}$ (13). Speci- mens were kept in the freezer for at least $24 \mathrm{~h}$ before being thawed and treated with PUV-A.

Frozen specimens were thawed in a $37^{\circ} \mathrm{C}$ water bath with continuous agitation until completely melted, and then $40 \mathrm{~mL}$ warm RPMI-1640 + $10 \%$ FCS was added directly into the cryobag. Cells were transferred into a Falcon 50 and centrifuged $\left(800 \mathrm{~g}\right.$ for $10 \mathrm{~min}$ at $25^{\circ} \mathrm{C}$ ) to remove the DMSO, then washed twice in $50 \mathrm{~mL}$ PBS. The cells were resuspended in RPMI-1640 and exposed 
to PUV-A. The cells (frozen/thawed PBMC) were then assessed for viability by trypan blue dye exclusion, and counted.

\section{Immunomodulation with PUV-A-treated donor cells (second MLR)}

After a 7-day culture, cells were harvested from the first MLR and treated by ECP. A second MLR was performed with $5 \times 10^{4}$ fresh stimulator cells (irradiated at $30 \mathrm{~Gy}$ ) from the same recipient as the initial MLR $\left(\mathrm{R}^{*}\right)$ and $1 \times 10^{5}$ CFSE-labeled cells from $\mathrm{D}\left(\mathrm{D}_{\mathrm{CFSE}}\right) .1 \times 10^{5}$ naive or previously sensitized ECP-treated 'immunomodulatory' cells from $\mathrm{D}$ were added on day 0 of the culture. The cell ratio was 1:2:2. Cells were cultured for 7 days in 96-well round-bottom plates in $250 \mu \mathrm{L}$ Dutch-modified RPMI-1640 supplemented with $10 \%$ FCS, L-glutamine, streptomycin and penicillin, and then cells were analyzed by flow cytometry (Beckman-Coulter EPICS, Roissy, France). Each point was performed in triplicate.

\section{Apoptosis}

Fluroescein isothiocyanate (FITC)-conjugated annexin-V (annexin) coupled with phycoerythrin (PE)-labeled 7-aminoactinomycin D (7AAD; Beckman-Coulter) was used to detect apoptosis. Cells were washed twice in PBS then stained with annexin/7AAD (in $100 \mu \mathrm{L}$ labeling solution) and incubated for $10 \mathrm{~min}$ in the dark according to the manufacturer's protocol. Then $400 \mu \mathrm{L}$ buffer were added, and stained cells ( $>1000$ events) were analyzed by flow cytometry (Beckman-Coulter EPICS). This staining protocol makes it possible to differentiate cells in early apoptosis (annexin ${ }^{+} / 7 \mathrm{AAD}^{-}$) and late apoptosis (annexin ${ }^{+} / 7 \mathrm{AAD}^{+}$) and necrotic cells $\left(\right.$ annexin $\left.-/ 7 \mathrm{AAD}^{+}\right)$from viable cells (annexin ${ }^{-} /$ $\left.7 \mathrm{AAD}^{-}\right)$.

\section{Mitogen-induced proliferation assay of ECP-treated cells}

After thawing, cells were placed on RPMI with phytohemagglutinin (PHA) at $10 \mu \mathrm{g} / \mathrm{mL}$. After a 3-day incubation period, $1 \mu \mathrm{Ci}{ }^{3} \mathrm{H}$-thymidine (Amersham, Pantin, France) was added to each well. Eight hours later, DNA was transferred onto filter paper using a multiwell harvester, and ${ }^{3} \mathrm{H}$ thymidine incorporation was measured in counts per minute (c.p.m.) using a gas-ionization counter. Proliferation was calculated as the mean value of triplicates, and inhibition was calculated as: [(c.p.m. before ECP - c.p.m. after ECP) $\times 100 /$ c.p.m. before ECP].

\section{Statistical analysis}

The experiments were repeated six times. The data presented show the mean of these six experiments. The error bars on the bar charts gives standard deviations (SD). Comparisons between fresh and frozen cells were run by paired $t$-test using SEM software (14).

\section{Results}

\section{ECP induces cell apoptosis}

Induction of lymphocyte apoptosis is a hallmark of ex vivo exposure to ECP. As soon as $2 \mathrm{~h}$ after ECP, the proportion of cells staining positive for annexin and negative for 7AAD was higher in ECP-treated cells compared with non-treated cells $(24.8 \pm 4 \%$ versus $18.4 \pm 5 \%, P<0.05)$. Annexin/7AAD staining was performed on each day of a 6-day culture. The percentage of annexin ${ }^{+}$cells remained higher in ECP-treated cells from day $1(69.1 \pm 4 \%$ versus $25.7 \pm 2 \%$, respectively) until day $6(95.9 \pm 4 \%$ versus $52.3 \pm 5 \%, P<0.001)$. The rate of late apoptotic cells (staining positive for both annexin and 7AAD) among ECP-treated cells was also increased compared with non-treated cells $(2 \mathrm{~h}, 3.9 \pm 0.4 \%$ versus $2.7 \pm 0.9 \%, P=\mathrm{NS} ; 6$ days, $55.5 \pm 5 \%$ versus $29.5 \pm 6 \%, P<0.01$ ) (Figure 2 ).

\section{Prior cryopreservation does not impair ECP-induced lymphocyte apoptosis}

Rapid and massive lymphocyte apoptosis is thought to be of major importance for the action of ECP. It was therefore necessary to assess whether ECP triggers apoptosis in cryopreserved cells as in fresh cells. We used fresh cells collected from six donors. Cells

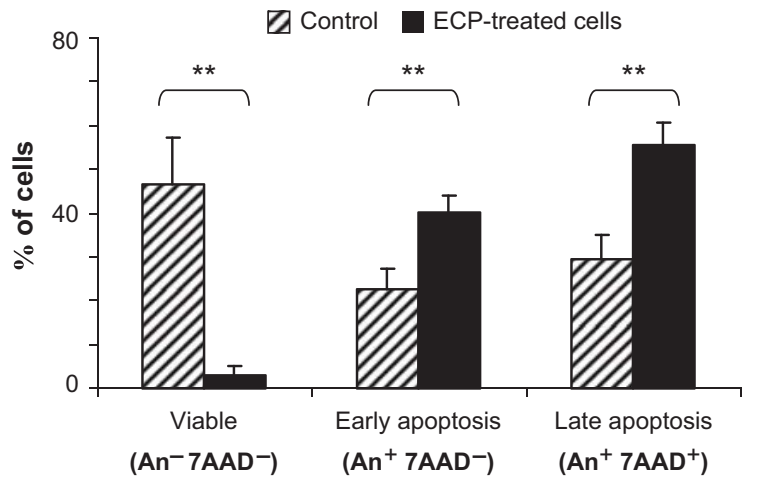

Figure 2. ECP induces apoptosis. PBMC were collected from healthy donors and cultured in 96-well plates in RPMI supplemented with FCS, glutamine and ATB. After 6 days of culture, apoptosis was measured by annexin/7AAD labeling, allowing differentiation of cells in early apoptosis (annexin ${ }^{+} / 7 \mathrm{AAD}^{-}$) and late apoptosis $\left(\right.$ annexin $^{+} / 7 \mathrm{AAD}^{+}$) from viable cells (annexin ${ }^{-}$ $\left./ 7 \mathrm{AAD}^{-}\right) .{ }^{* *} P<0.01$ 
were exposed to ECP after having been cryopreserved or not, then cultured for 6 days and apoptosis measured at different time points. In cryopreserved ECP-treated cells, the rate of early apoptosis was slightly increased compared with ECP-treated fresh cells immediately after ECP $(27.1 \pm 4 \%$ versus 20.0 $\pm 2 \%, P<0.05)$. This small increase in apoptosis persisted for 3 days, and was no longer significant thereafter (Figure 3). At any time of the study, the rate of necrotic cells (annexin-/7AAD+) was less than $1 \%$.

\section{ECP-treated cells slightly inhibit alloreactive proliferation}

CFSE-loading makes it possible to quantify precisely the level of alloreactive proliferation by measuring the proportion of dividing CFSE ${ }^{\text {low }}$ and quiescent CFSE ${ }^{\text {bright }}$ cells in the gate of viable lymphocytes (11). Quiescent cells (CFSE ${ }^{\text {bright }}$ ) were higher in the autologous controls $\left(\mathrm{D}_{\mathrm{CFSE}} \times \mathrm{D}^{*}\right)$ than in the allogeneic MLR $\left(D_{\text {CFSE }} \times R^{*}\right)$, reflecting a higher proliferation rate in the second: $81.2 \pm$ $2.6 \%$ versus $50.3 \pm 8.5 \%$, respectively, $P<0.01$ (Figure 4). When ECP-treated naive D cells were added (on day 0 ) to the culture well, proliferation was slightly but significantly decreased (CFSE ${ }^{\text {bright }}$, $57.9 \pm 9.3 \%$ versus $50.3 \pm 8.5 \%$, respectively, $P<0.05)$.

\section{Prior sensitization optimizes the ECP-induced anti-proliferative effect}

ECP is believed to result in the selective neutralization of pathogenic T-cell clones. Moreover, activated lymphocytes are more susceptible to cell death after ECP exposure (D. Hannani, manuscript in preparation) and their immunomodulatory capabilities exceed those of non-activated cells (15). When a patient with GvHD is treated with ECP, the ECP-treated bag contains alloreactive and resting mononuclear donor cells. Thus, to get closer to the clinical setting of active GvHD, we considered mimicking in vitro the step of preECP alloreactive activation. To obtain alloreactive activated cells, donor cells were primarily exposed to receiver cells in a first MLR (Figure 1). We therefore assessed whether prior allogeneic stimulation could enforce the anti-proliferative effect of ECP-treated cells. In our model, the inhibition of alloreactive proliferation was stronger when the ECP-treated mononuclear cells had been activated previously by cells from the same donor than with naive cells (CFSE ${ }^{\text {bright }}$ non-reactive cells, $77.5 \pm$ $16.3 \%$ versus $57.9 \pm 9.3 \%$, respectively, $P<0.01$ ) (Figure 4).
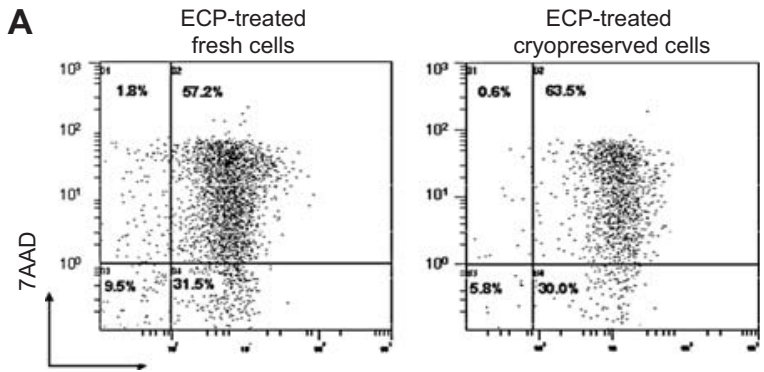

Annexin-FITC
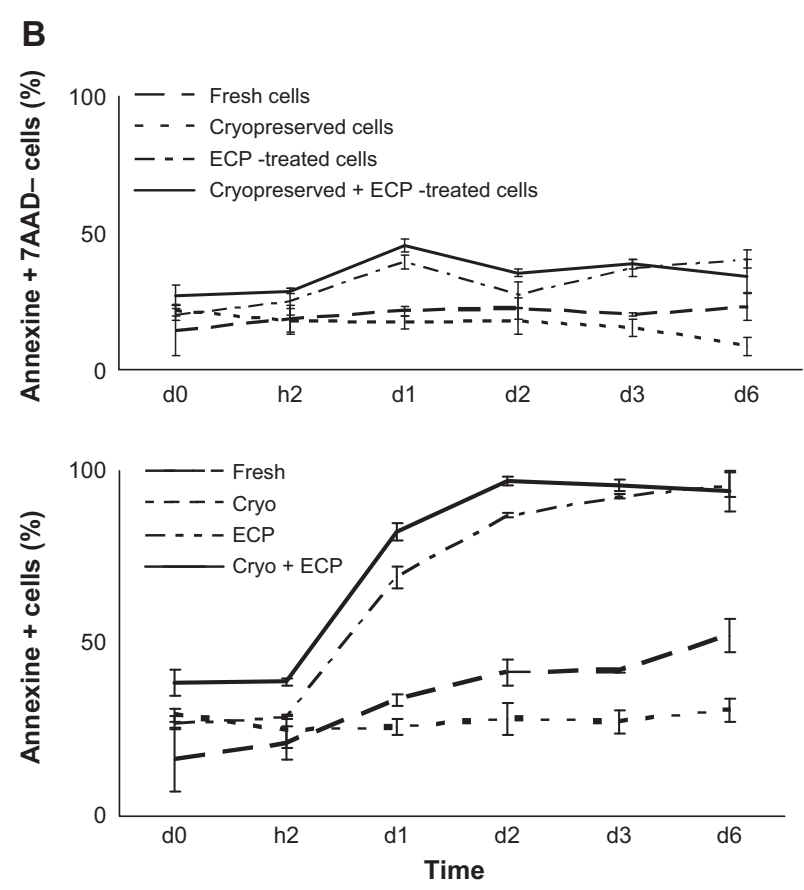

Figure 3. Cryopreservation slightly increases the percentage of apoptotic cells after exposure to ECP for 3 days. PBMC were collected from six healthy donors and frozen at $-80^{\circ} \mathrm{C}$ in an icecold cryoprotective solution containing 7\% DMSO, 10\% serum albumin and $83 \%$ hydroxyethylstarch. After $24 \mathrm{~h}$ at $-80^{\circ} \mathrm{C}$, cells were thawed, washed twice in PBS and exposed to ECP. Apoptosis was then measured at various time points. (A) One representative experiment in presented. Fresh or cryopreserved ECP-treated cells were labeled with annexin and 7AAD at day 2 . The staining protocol made it possible to differentiate cells in early apoptosis $\left(\right.$ annexin $\left.^{+} / 7 \mathrm{AAD}^{-}\right)$, cells in late apoptosis (annexin ${ }^{+} / 7 \mathrm{AAD}^{+}$) and necrotic cells (annexin ${ }^{-} / 7 \mathrm{AAD}^{+}$) from viable cells (annexin $\left./ 7 \mathrm{AAD}^{-}\right)$. (B) The kinetics of apoptosis of fresh and cryopreserved cells treated or not by ECP are presented for $2 \mathrm{~h}$ and 1,2,3 and 6 days. Upper panel, percentage of early apoptotic cells $\left(\right.$ annexin $\left.{ }^{+} / 7 \mathrm{AAD}^{-}\right)$; lower panel, percentage of total apoptotic cells $\left(\right.$ annexin $\left.{ }^{+}\right) ;{ }^{*} P<0.05$ (cryopreserved cells versus fresh cells).

Cryopreservation before ECP does not impair the inhibition of PHA-induced lymphocyte proliferation

PHA is a non-specific mitogen activator of T cells. It binds the T-cell receptor and is able to trigger a massive activation and proliferation of the whole lymphocytic population. The impairment of PHA-induced lymphocyte proliferation is a currently used quality 

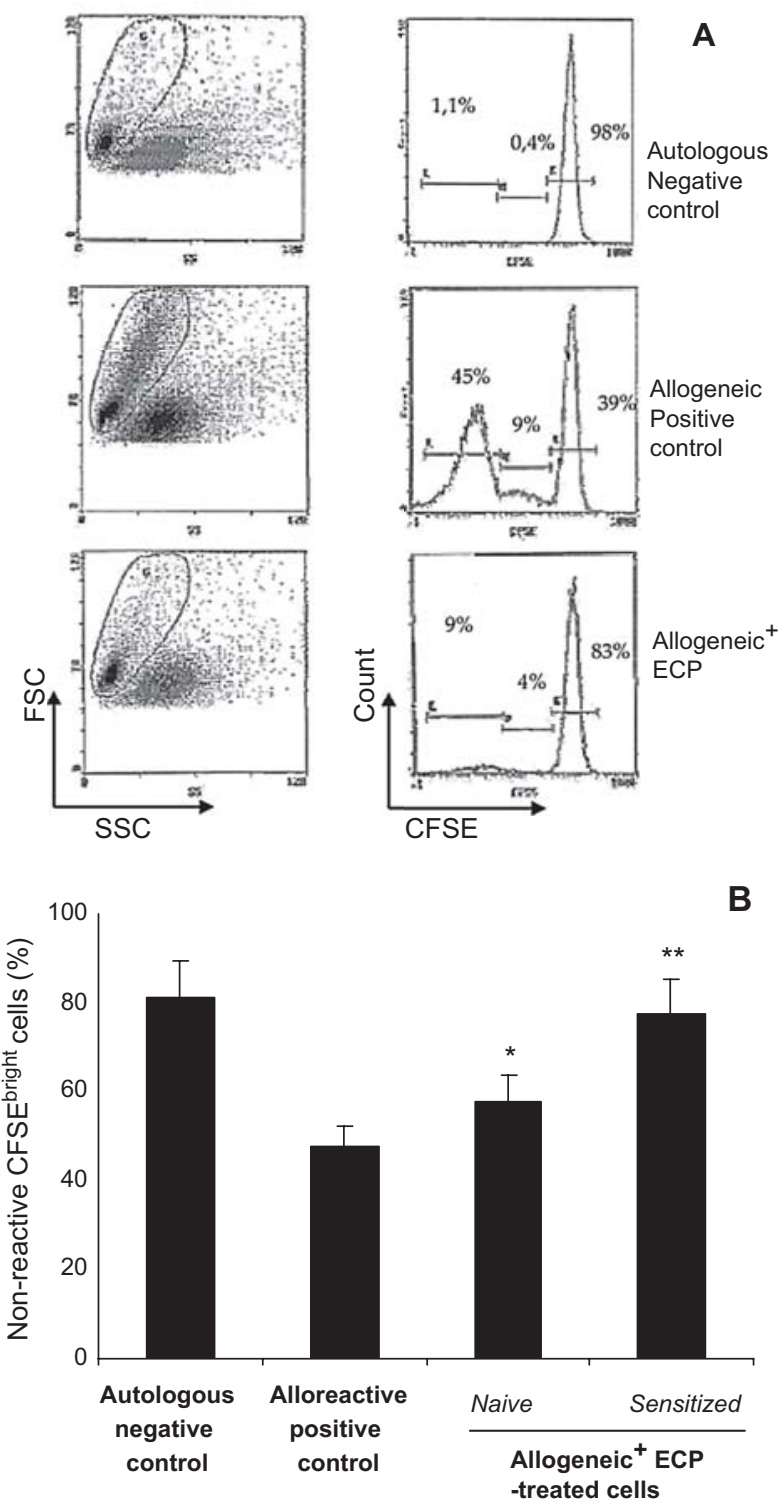

Figure 4. ECP-treated cells inhibit allogeneic proliferation in an MLR. PBMC were collected from six couples of healthy volunteers. Responsive D cells were labeled with $1 \mu \mathrm{mol} / \mathrm{L}$ CFSE $\left(\mathrm{D}_{\mathrm{CFSE}}\right)$ and cultured for 7 days with stimulator cells $\mathrm{R}^{*}$ (irradiated at $30 \mathrm{~Gy}$ ) and ECP-treated cells (added on day 0 of culture). ECPtreated cells were from $\mathrm{D}$ and were naive or had been previously sensitized in a previous 7-day MLR with $R^{*}$. The ratio between $\mathrm{R}^{*}, \mathrm{D}_{\mathrm{CFSE}}$ and ECP-treated cells was 1:2:2. (A) One representative experiment; (B) results of the six experiments. Compared with allogeneic control: ${ }^{*} P<0.05 ;{ }^{* *} P<0.01$.

control for the procedure of ECP (16). We therefore assessed whether prior cryopreservation would impact this effect of ECP. Using PHA at a concentration of $10 \mu \mathrm{g} / \mathrm{mL}$, proliferation was achieved in all cryopreserved samples $(99357 \pm 8524$ c.p.m. versus $133 \pm 55$ without PHA). After the ECP process, inhibition was complete $(132 \pm 61$ c.p.m. versus $32 \pm 25$ without PHA, 99\% inhibition) (data not shown).
Previously cryopreserved cells retain their anti-proliferative properties when treated by ECP after thawing

The ultimate aim of our study was to determine whether cryopreserved PBMC retain their immunomodulatory properties when treated by ECP after being thawed. Knowing the activated state of lymphocyte responsible of active GvHD, we used the same manipulation with a first MLR to sensitize PBMC from $\mathrm{D}$ to $\mathrm{R}$, followed by a second MLR to measure the inhibition of alloreactive proliferation provided by ECP-treated cells. After the second MLR, the rate of non-dividing $\mathrm{CFSE}^{\text {bright }}$ cells was $47.8 \pm 12 \%$ in allogeneic controls. The inhibition of alloreactive proliferation induced by ECP-treated cells resulted in a significant increase of non-dividing cell rate. This inhibition was similar whether ECP-treated cells had been previously cryopreserved or not: non-dividing CFSEbright cells $68.6 \pm 26 \%$ versus $64.5 \pm 10 \%$ with cells sensitized before ECP $(P=0.8)$ and $60.6 \pm 9 \%$ versus $57.9 \pm 9 \%$ with ECP-treated cells without previous sensitization $(P=0.7)$ (Figure 5$)$. The inhibition of proliferation was given by the following formula: percentage inhibition $=100 \times\left(\mathrm{CFSE}^{\text {bright }}{ }_{\mathrm{ECP}}-\right.$ $\mathrm{CFSE}^{\text {bright }}{ }_{\text {control }} / \mathrm{CFSE}^{\text {bright }}$ control; where ECP is the culture with ECP-treated cells and control is the control MLR without ECP-treated cells. Inhibition was similar between fresh and cryopreserved cells $(24.6 \pm$ $16 \%$ versus $32.2 \pm 30 \%$, respectively, $P=0.6$ ).

\section{Discussion}

ECP is a fascinating immunotherapy that uniquely provides a selective immune regulation without generalized immune suppression (2). The beneficial effects of the method have been observed in a variety of T-cell mediated inflammatory diseases, such as GvHD, transplant rejection and certain T-cell mediated autoimmune diseases (17). However, its clinical use is limited by logistical difficulties, especially because of the need to perform repeated aphereses. This problem is of particular importance for small children for whom reducing exposure to conventional immunosuppressive therapies is especially warranted (10).

One approach to reducing the number of apheresis sessions while maintaining the treatment schedule is to use cryopreserved cells, as illustrated in Figure 6. For example, the cell product harvested in one apheresis can be divided into three aliquots: two can be cryopreserved while the third can be treated immediately and reinfused. This approach offers four advantages: (a) it makes ECP easier for the patients; (b) it takes advantage of the temporary use of a central venous line to harvest a large quantity of cells; (c) it allows patients from other care centers to benefit easily from ECP 


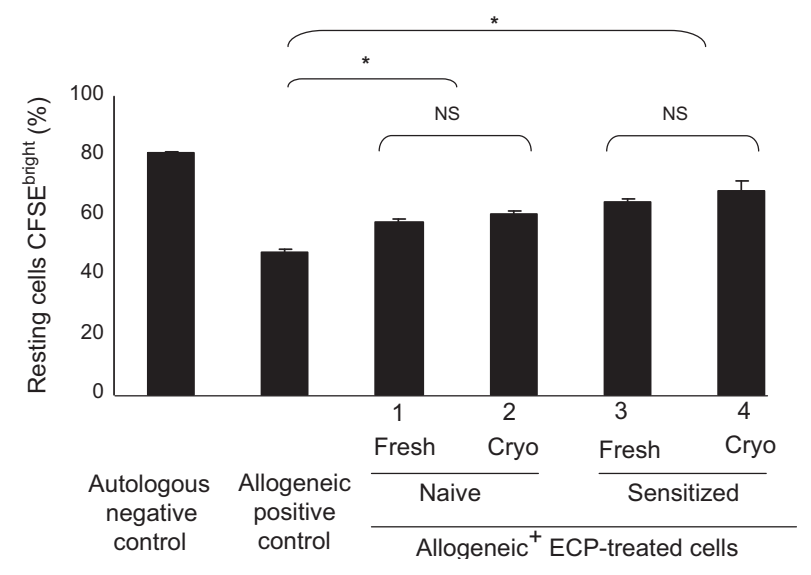

Figure 5. Previously cryopreserved mononuclear cells retain their anti-proliferative properties when treated with ECP. Six couples of healthy volunteers were enrolled. PBMC from healthy volunteer $\mathrm{D}$ were labeled with CFSE, whereas PBMC from healthy $\mathrm{R}$ were irradiated at $30 \mathrm{~Gy}$ and used as stimulators. ECP-treated cells were added on day 0 of the 7-day culture. The ratio between $\mathrm{R}^{*}$, $\mathrm{D}_{\mathrm{CFSE}}$ and ECP-treated cells was 1:2:2. ECP-treated cells were: (1) fresh naive cells from D; (2) cryopreserved naive cells from D; (3) fresh cells from D previously sensitized by a 7-day MLR, $\mathrm{D} \times \mathrm{R}^{*}$; (4) cryopreserved cells from $\mathrm{D}$ previously sensitized by a 7-day MLR, $\mathrm{D} \times \mathrm{R}^{*} .{ }^{*} 1,2,3$ and 4 versus allogeneic control, $P<0.05 ; 1$ versus 2 and 3 versus $4, P=$ NS.

therapy; (d) it allows standardization of the quantity of cells infused at each session. Here we have shown that cryopreserved cells retain their immunomodulatory capabilities when treated by ECP.
The main drawback of cryopreservation is that it implies an overall decrease in total cell dose. However, if the aphereses are spaced out, the price to pay to harvest more cells (stronger platelet depletion) becomes acceptable. In our center, the mean duration of one apheresis for ECP is about $100 \mathrm{~min}$. If the frequency of aphereses decreases from three a week to one a week, it becomes possible to lengthen one session to up to $150 \mathrm{~min}(+50 \%)$. Moreover, increasing the total volume collected can enhance collection efficiency by about $20 \%$. Overall, the total cell dose can be maintained at about $60 \%$ for each reinfusion while the treatment schedule is maintained with three times fewer aphereses sessions. Although suggested previously (18), the effect of the cell dose has never yet been clearly established. By allowing a standardization of the cell dose for each reinfusion, cryopreservation can provide insightful data regarding this question. Another theoretical issue can stem from the toxicity of repeated DMSO infusions. In our procedure, cells were frozen in a low DMSO cryoprotective solution (only 3.5\%) and the cells washed before reinfusion. As a result, we assume that the toxicity of DMSO would be negligible, but this warrants rigorous assessment in clinical safety trials.

The prospects for clinical use make it critical to determine the in vitro impact of cryopreservation on the properties of ECP-treated cells as a pre-clinical measure. The first reported phenomenon is the massive induction of lymphocyte apoptosis after ECP

A To date

Monday 9h-13h
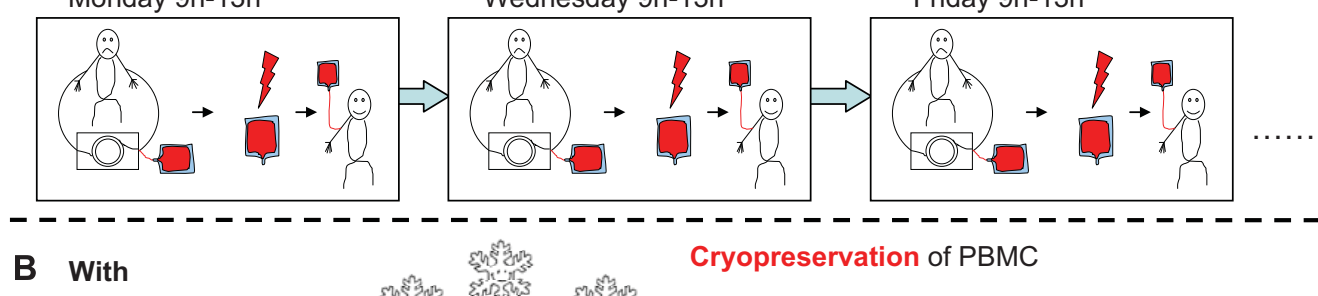

cryopreservation

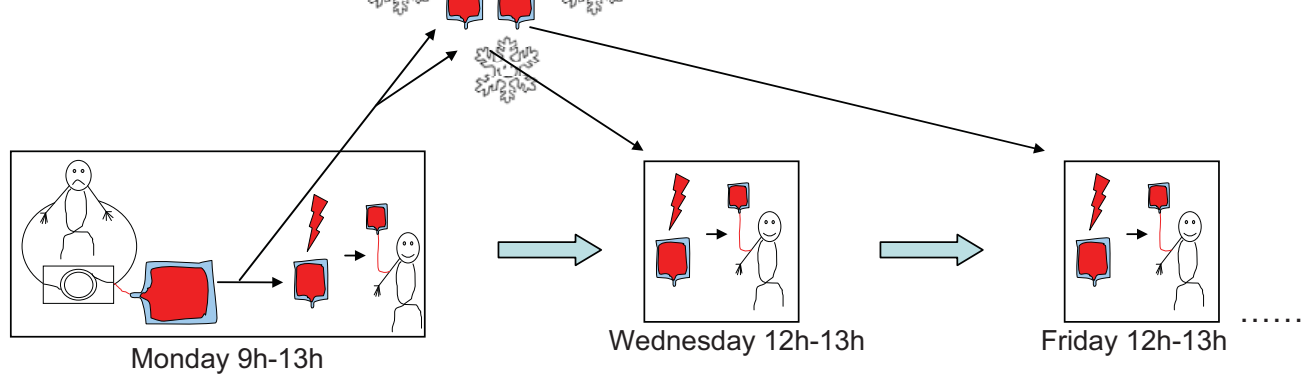

ECP and Reinfusion

of fresh cells

Thawing, ECP and Reinfusion of cryopreserved MNC

Figure 6. Clinical application of cryopreserved PBMC for ECP. (A) Currently, in a schedule based on three sessions a week, three aphereses are performed (Monday, Wednesday and Friday). (B) Scheme of the same ECP schedule using cryopreservation: only one apheresis (Monday) should be necessary. 
exposure (19). Apoptotic cells are engulfed by treated or untreated phagocytes and dendritic cells, which are thought to trigger a regulatory immune response. In certain conditions, cryopreservation is known to trigger lymphocyte apoptosis (20) and to preserve the stimulatory function of dendritic cells $(21,22)$. To assess whether cryopreserved cells retain their immunomodulatory properties after ECP, we built an in vitro model that is applicable to healthy humans and is easy to exploit. It is known that the adjunction of ECP-treated cells in an allogeneic MLR results in an inhibited alloreactive proliferation (23). As the mechanism of action of ECP remains largely unknown, we chose to measure functional inhibition of alloreactive proliferation. Our model demonstrates a significant inhibition of alloreactive proliferation by ECP-treated cells, and this effect is retained even when cells have been cryopreserved before ECP. We therefore believe that the advantages and disadvantages of using cryopreserved PBMC for ECP in clinical practice deserve to be investigated.

\section{Acknowledgements}

This work was supported by the association 'Capucine' (grant attributed under the control of the association 'Centpoursanglavie'). We thank Magalie Diviné, Florence Jacomet and Camille Confland for technical assistance.

Disclosure of interest: The authors have no conflict to declare.

\section{References}

1. Halle P, Paillard C, D'Incan M, Bordigoni P, Piguet C, De Lumley L, et al. Successful extracorporeal photochemotherapy for chronic graft-versus-host disease in pediatric patients. J Hematother Stem Cell Res. 2002;11:501-12.

2. Marshall SR. Technology insight. ECP for the treatment of GvHD: can we offer selective immune control without generalized immunosuppression? Nat Clin Pract Oncol. 2006;3: 302-14.

3. Plumas J, Manches O, Chaperot L. Mechanisms of action of extracorporeal photochemotherapy in the control of GVHD: involvement of dendritic cells. Leukemia. 2003;17:2061-2.

4. Hannani D, Gabert F, Laurin D, Sall M, Molens J, Hequet $\mathrm{O}$, et al. Photochemotherapy induces the apoptosis of monocytes without impairing their function. Transplantation. 2010 89:492-9.

5. Maeda A. Extracorporeal photochemotherapy. J Dermatol Sci. 2009;54:150-6.

6. Jonson CO, Pihl M, Nyholm C, Cilio CM, Ludvigsson J, Faresjo M. Regulatory T cell-associated activity in photopheresis-induced immune tolerance in recent onset type 1 diabetes children. Clin Exp Immunol. 2008;153:174-81.

7. Edelson R, Berger C, Gasparro F, Jegasothy B, Heald P, Wintroub B, et al. Treatment of cutaneous T-cell lymphoma by extracorporeal photochemotherapy. Preliminary results. N Engl J Med. 1987;316:297-303.
8. Guyot AD, Farhi D, Ingen-Housz-Oro S, Bussel A, Parquet $\mathrm{N}$, Rabian C, et al. Treatment of refractory erosive oral lichen planus with extracorporeal photochemotherapy: 12 cases. $\mathrm{Br}$ J Dermatol. 2007;156:553-6.

9. Andreu G, Leon A, Heshmati F, Tod M, Menkes CJ, Baudelot J, et al. Extracorporeal photochemotherapy: evaluation of two techniques and use in connective tissue disorders. Transfus Sci. 1994;15:443-54.

10. Kanold J, Merlin E, Halle P, Paillard C, Marabelle A, Rapatel C, et al. Photopheresis in pediatric graft-versus-host disease after allogeneic marrow transplantation: clinical practice guidelines based on field experience and review of the literature. Transfusion. 2007;47:2276-89.

11. Evrard B, Dosgilbert A, Jacquemot N, Demeocq F, Gilles T, Chassagne J, et al. CFSE flow cytometric quantification of lymphocytic proliferation in extracorporeal photopheresis: use for quality control. Transfus Apher Sci. 2010;42:11-9.

12. Lyons $\mathrm{AB}$. Analysing cell division in vivo and in vitro using flow cytometric measurement of CFSE dye dilution. J Immunol Methods. 2000;243:147-54.

13. Halle P, Tournilhac O, Knopinska-Posluszny W, Kanold J, Gembara P, Boiret N, et al. Uncontrolled-rate freezing and storage at -80 degrees $\mathrm{C}$, with only 3.5-percent DMSO in cryoprotective solution for 109 autologous peripheral blood progenitor cell transplantations. Transfusion. 2001;41:667-73.

14. Kwiatkowski F, Girard M, Hacene K, Berlie J. [Sem: a suitable statistical software adapted for research in oncology]. Bull Cancer. 2000;87:715-21.

15. Stadler K, Frey B, Munoz LE, Finzel S, Rech J, Fietkau R, et al. Photopheresis with UV-A light and 8-methoxypsoralen leads to cell death and to release of blebs with anti-inflammatory phenotype in activated and non-activated lymphocytes. Biochem Biophys Res Commun. 2009;386:71-6.

16. Jacob M, Manches O, Drillat P, Richard M, Plumas J, Chaperot L, et al. Quality control for the validation of extracorporeal photopheresis process using the Vilbert-Lourmat UV-A irradiation's system. Transfus Apher Sci. 2003;28:63-70.

17. Szodoray P, Papp G, Nakken B, Harangi M, Zeher M. The molecular and clinical rationale of extracorporeal photochemotherapy in autoimmune diseases, malignancies and transplantation. Autoimmun Rev. 2010;9:459-64.

18. Perseghin P, Galimberti S, Balduzzi A, Bonanomi S, Baldini V, Rovelli A, et al. Extracorporeal photochemotherapy for the treatment of chronic graft-versus-host disease: trend for a possible cell dose-related effect? Ther Apher Dial. 2007;11:85-93.

19. Yoo EK, Rook AH, Elenitsas R, Gasparro FP, Vowels BR. Apoptosis induction of ultraviolet light $\mathrm{A}$ and photochemotherapy in cutaneous T-cell lymphoma: relevance to mechanism of therapeutic action. J Invest Dermatol. 1996;107:235-42.

20. Sarkar S, Kalia V, Montelaro RC. Caspase-mediated apoptosis and cell death of rhesus macaque $\mathrm{CD} 4+\mathrm{T}$-cells due to cryopreservation of peripheral blood mononuclear cells can be rescued by cytokine treatment after thawing. Cryobiology. 2003;47:44-58.

21. Westermann J, Korner IJ, Kopp J, Kurz S, Zenke M, Dorken $\mathrm{B}$, et al. Cryopreservation of mature monocyte-derived human dendritic cells for vaccination: influence on phenotype and functional properties. Cancer Immunol Immunother. 2003;52: 194-8.

22. Feuerstein B, Berger TG, Maczek C, Roder C, Schreiner D, Hirsch U, et al. A method for the production of cryopreserved aliquots of antigen-preloaded, mature dendritic cells ready for clinical use. J Immunol Methods. 2000;245:15-29.

23. Perez MI, Edelson RL, John L, Laroche L, Berger CL. Inhibition of antiskin allograft immunity induced by infusions with photoinactivated effector $\mathrm{T}$ lymphocytes (PET cells). Yale J Biol Med. 1989;62:595-609. 